\title{
The Virtual Tutor: Tasks for conversational agents in Online Collaborative Learning Environments
}

\author{
Christian Gabriel \\ TU Dresden \\ christian.gabriel1@ \\ mailbox.tu-dresden.de
}

\author{
Charlotte Hahne \\ TU Dresden \\ charlotte.hahne@ \\ mailbox.tu-dresden.de
}

\author{
Alina Zimmermann \\ TU Dresden \\ alina.zimmermann@ \\ $\underline{\text { mailbox.tu-dresden.de }}$
}

\author{
Florian Lenk \\ TU Dresden \\ florian.lenk@ \\ $\underline{\text { tu-dresden.de }}$
}

\begin{abstract}
Online collaborative learning environments are becoming increasingly popular in higher education. Etutors need to supervise, guide students and look out for conflicts within the online environment to ensure a successful learning experience. Web-based platforms allow for interactive elements such as conversational agents to disencumber the e-tutor. Repeatable tasks, which do not require a human response, can be automatized by these systems. The aim of this study is to identify and synthesize the tasks an e-tutor has and to investigate the automatisation potential with conversational agents. Using a design science research approach a literature review is conducted, identifying 13 tasks. Subsequently, a matrix is established, contrasting the tasks with requirements for the use of conversational agents. Furthermore, a virtual tutor framework is developed, clarifying the agent type selection, the technical structure and components for a prototype development in an online collaborative learning environment.
\end{abstract}

\section{Introduction}

Higher education institutions are increasingly incorporating online collaborative learning environments in university courses [26]. These environments enable a location independent and time flexible working style for students as well as prepare the participants for the digital and collaborative knowledge work in their future professional life [43]. Changing from the physical to the online world, teachers and tutors face various organizational and didactical tasks and challenges in the online collaborative learning environments. This includes preparing the course materials and making them available in the online environment, preparing the learners for a digital way of working, answering questions and steering discussions. Furthermore, guiding learners and looking out for conflicts in the groups as well as answering organizational and technical questions are essential tasks to create a successful learning environment [6].

The use of online platforms allows the implementation of pedagogical conversational agents, which have been of increasing interest for the scientific community over the last decade [27]. They have been applied in various disciplines such as physics, mathematics, languages and chemistry, usually inspired by gamification-related pedagogical strategies [15]. In general, chat-based processes are well accepted by users. According to recent studies, over $90 \%$ of those interviewed use messenger services, $70 \%$ on a daily basis, proving that users are already acquainted with natural language based learning [45]. Conversational agents in production environments have already successfully optimized the processes in areas such as marketing, customer support or content search [4]. With this technology, user requests can be answered automatically, or, alternatively, the conversational agent can initiate an automated dialogue. However, including conversational agents in online collaborative learning environments has not been a focus of recent research, even though it offers a variety of benefits [24].

Implementing conversational agents in online collaborative learning environments can support and relieve e-tutors by carrying out tasks that occur repeatedly or do not require a human response. For example, workflows can be designed to search for content or provide information [40]. Through the connection of third-party systems and the development of pre-defined dialogue, even complex processes can be mapped. Thus, the e-tutors can focus on their core didactic activities [54]. For students, conversational agents make it possible to interact with automated systems in a simple and natural language. In addition, this technical support makes it easier for them to work independently as questions within the conversational agent's scope may be answered at any given time, increasing the didactical capacity of the e-tutors.

Conversational agents make it possible for users to interact with automated systems in a simple and natural 
language. For example, workflows can be designed to search for content or provide information [40]. Through the connection of third-party systems and the development of pre-defined dialogue processes, even complex processes can be mapped.

Consequently, the aim of this paper is to collect tasks of e-tutors in an online collaborative learning environment, to evaluate their replicability through conversational agents, and to provide recommendations, on how to prioritize tasks when developing a future prototype. In this research, the conversational agent is intended to focus on disencumbering the e-tutors and see the student as the user of the conversational agent. This leads to the following research questions:

- Which tasks exist for e-tutors in an online collaborative learning environment?

- Which identified tasks can text based conversational agents assume to support etutors?

To answer these research questions, the remainder of this paper is structured as follows. First, an overview of online collaborative learning environments and conversational agents is given. Based on this background, section 3 describes the research approach of the literature review for identifying tasks of e-tutors. Subsequently, a conversational agent type was selected based on the technical possibilities in online collaborative learning environments and the state-ofthe-art in conversational agent creation. Combining the findings, a virtual tutor framework was developed to evaluate whether a conversational agent based on the selected type can automate the tasks. Finally, we briefly summarize the results and give an outlook for application areas and further research.

\section{Background and related works}

\subsection{Online collaborative learning environments and e-tutors}

The use of online collaborative learning environments is increasingly adopted and implemented by educational institutions, to foster synchronous and asynchronous collaborative learning. Since there is no widely accepted definition of these environments, the literature provides a variety of terms and interpretations, such as computer mediated communication (CMC) [39], learning management system (LMS) [37] or virtual collaborative learning (VCL) [5].

According to Herrera [37], online collaborative learning environments are "virtual spaces that teachers and students can use to present and share resources and activities and interact with one another" [37]. The focus is to use the online collaboration tools available in the environment to enable spatially separated group work. During the development of a solution, the students research functional information, evaluate their findings and decide on viable results [25].

In the context of collaborative learning, in which students can become an active part of online discussions, supervision is vital for successful learning $[9,32]$. Depending on the role and integration into the organizational framework, the tasks of e-tutors vary.

The relevant literature employs multifarious terms for e-tutors. The termini teacher, online teacher, instructor, facilitator, tutor, and e-tutor are used in literature and are named e-tutors in this study. The focus for this publication is to inquire task automation for etutors via conversational agents [14, 41, 51, 53].

According to Goold et al. [21], tutors in online collaborative learning environments mainly accomplish tasks such as keeping discussions focused, responding to student queries and technical issues, providing feedback or observing group processes [21, 39]. However, another main aspect for e-tutors is to monitor the communication and activity patterns of the groups and individual students [46]. From these patterns, etutors deduce interventions to maximize the skill acquisition in the course on a personal and group level. This means they are not only observing the activity but also giving feedback, motivating and moderating the teamwork and resolving problems and conflicts. Furthermore, the e-tutor guides the students towards adaptability, professional, team and media competence [28].

The web-based platforms provide a range of opportunities and functionalities, which support e-tutors to convey portions or entire course lessons as well as help with the described tasks in distant education. For example, interactive elements and external tools are integrated to foster communication and computersupported collaborative work, such as chats, synchronous document editing, forums and videoconferencing [37]. The data generated on these platforms can display an overview of the activity and communication patterns, which e-tutors need to supervise the learning environment effectively. The online platforms also enable conversational agents to be implemented in the environment to assume tasks, which can be automatized.

\subsection{Conversational agents}

Conversational Agents are systems that can automatically respond to requests from users. They enable communication between computer and human beings. The system can react independently to natural 
language (both spoken language and written language) without the need for human assistance [49].

The design, implementation and strategies of conversational systems varies depending on the objectives. In general, conversations are conveyed using simple text based forms. The programs can appear in different forms, for example as a speech bubble or figure, depending on the development effort spent and if they use text or speech to communicate. Other systems implement embodied conversational agents, which are able to display gesture and emotion [31]. The development effort depends on the extent natural language processing is incorporated in the functionality of the conversational agent, providing the user with more flexibility in the communication [49]. Up to now, conversational agents are mainly used on websites or in messaging apps of companies and partly internally to support employees in their daily tasks [16].

From a pedagogical perspective, a conversational agent helps to provide learning support to learners and is a vital part in the individualization of learning processes. [27] They help to promote reflection and meta-cognitive skills. Tutoring tactics enable the learner to construct knowledge actively and to maintain motivation throughout the interaction.

The purpose of a conversational agent is divided into goal-oriented and non-goal-oriented purposes. The latter is necessary to keep users content with small talk whereas the former serves to support the user in concrete issues rather than social interaction.

There are different approaches to subdivide the functionality of conversational agents. One possibility describes the rule-based and data-based functionality. The first group of rule-based conversational agents maintain their communication according to firmly defined patterns and rules. Therefore, only certain inputs can be processed and only outputs defined by the developer can be generated. When programming, all input and output options must be considered. As a result, the user usually must choose from a list of options and cannot enter text freely. In contrast, databased conversational agents use machine learning to process information that is not explicitly implemented in the system beforehand. This allows these conversational agents to react flexibly to the user's request [50].

\section{Research methodology}

In this paper, a first concept of how to use conversational agents in online collaborative learning environment shall be developed. To conduct the research, a DSR approach is applied, based on the first three steps of the process model by Peffers et al. [42]: 1) problem identification and motivation, 2) definition of objectives for a solution, 3) design and development. Problem identification and motivation has been described in the previous sections. To define the objectives of the solution, the conversational agent, it is important to research, which tasks the conversational agent can manage. Therefore, it is necessary to gain an overview of the current tasks of e-tutors in the field of online collaborative learning and to link these with possible applications of conversational agents.

To gain this overview of tasks, a literature search, based on a reference list search strategy, was chosen, because it refers to a defined field with strong internal connections [48]. One central paper with a focus on online collaborative learning with e-tutors was chosen as a starting point, since the probability of identifying rule-based tasks is highest here. This paper is "An examination of the role of the e-tutor" by Goold et al. [21]. Originating from this publication, a two-stage backwards search and a single stage forward reference search was performed. The backwards search generated 37 results in the first backwards search and an additional 508 results in the second stage. The forward search generated 46 results.

\section{Table 1. Search, filtering and identification process}

\begin{tabular}{cc} 
Literature search and selection & $\begin{array}{c}\text { \# of } \\
\text { Publications }\end{array}$ \\
\hline Two stage backward search & 508 \\
Single stage forward search & 46 \\
\hline
\end{tabular}

Filtered by date (2000-2020), English,

peer-reviewed, high ranking based on

Scimago Jorunal \& Country Rank

\begin{tabular}{llll}
\hline Final result after relevance & 52 \\
\multicolumn{2}{l}{ assessment (Title, Abstract) } & \\
\hline
\end{tabular}

Identified tasks of e-tutors from final selection

The results were filtered by a publishing date between 2000 and 2020, the publication body being an English, peer-reviewed and high ranking based on the Scimago Journal \& Country Rank. This step narrowed the results down to 91 results. These publications were further filtered based on a relevance assessment of the title and abstract. Finally, 52 papers were included in the review. 13 tasks in online collaborative learning environments were identified from these 52 papers, answering the first research question. 
To assess which tasks can be automated a central publication for chatbot design was used [50]. First the agent type selection and secondly the virtual tutor preconditions need to be described. Using these requirements for use of conversational agents, the tasks for e-tutors were combined in a task identification model for the conversational agent. This resulted in a suggestion, which specifications should be included and are implementable in online collaborative learning environment courses.

\section{Conversational agents for online collaborative learning environments}

\subsection{Conversational agent type selection}

As a basis for the use of conversational agents in online collaborative learning courses, the first step is to determine the technical specification of the conversational agent. There are three main areas, in which a decision must be made: the form of input, i.e. text, speech or both, the method of intent recognition, i.e. the way the conversational agent interprets the user input and the action selection, whether only previously defined intents are handled or the conversational agent is able to recognize other intents independently [50].

Input Method: The basis for online collaborative learning environments is a technical platform containing a possibility to communicate between different users [3]. This includes both text-based and speech-based communication. However, the support of learning environments requires the input and output of complex content, which is easier to achieve and more readily available with text modules. Therefore, text based conversational agents are assumed in the following procedure.

Intent Recognition: For the present purpose, either a rule-based or a data-driven approach in combination with machine learning can be used [50]. The first variant severely limits the input in the form of menus. This means it is not possible to use more complex conversations, which contain key words for further workflows. In this case, a data-driven approach incorporating machine learning must be used [47].

Action Selection: There are two main types of how responses are generated, and dialogues are controlled. There is a choice between rule-based approaches, where the rules for answers are defined manually, and approaches based on machine learning [17]. For this initial model a rule-based approach is assumed, as it allows for a faster initial development an important consideration for prototyping [30]. The final development should include a machine-learning based approach, since natural language processing enables a more authentic user experience and increases the flexibility of conversations. However, as this first concept primarily aims to disencumber the e-tutors, a rule-based approach is sufficient.

As a result a conversational agent is assumed, which communicates text-based with the user for input and output, assigns the statement of the user to predefined intents, and reacts to these either with questions or direct answers based on predefined rules.

\subsection{Requirements for the use of conversational agents}

To determine whether a conversational agent can be used as a virtual tutor, preconditions must be defined.

Communication Task: Initially, the conversational agent must communicate with and understand the user in order to be able to take a request [44]. The input is then compared with given intents and the best fit is selected [20].

Initiated by Student: The user, in this case the student, must initiate the tasks of the conversational agent. The system cannot perform tasks without the trigger from the student. The student is assumed as the receiving user, as this conversational agent shall disencumber the e-tutor in the learning environment.

Action Based on Existing Data: To be able to handle a request, the conversational agent must possess certain competences. In order to access these, the system must be connected to a database with contextual, predefined contents [44].

Clear Reaction Process: Based on the detected intent, a rule-based conversational agent will execute a predefined reaction. In order to define this reaction, it is necessary that the process, being executed to react, is previously uniquely describable and can be provided with parameters [20]. Consequently, processes that require an individual assessment by the e-tutors cannot be modelled.

\section{Tasks of e-tutors in online collaborative learning environments}

The main task of e-tutors is to support learners in an online environment. Course Organization covers the most extensive task field of e-tutors in online collaborative learning environments. The studies show that general course management involves scheduling and facilitating of online groups in order to ensure the preconditions for a smooth course [6, 21, 29, 35]. The literature research yielded 13 different tasks. As previously mentioned, the focus of the specific tasks varies and depends on the role and integration into the organizational framework. 
Scheduling: includes the e-tutors' assistance regarding the general online course administration as well as the time and self-management of students. Therefore, the e-tutors are responsible for checking the participants' presence in the online collaborative learning environment, informing them about organizational issues and additionally setting up checkpoints or deadlines and reminding students of them $[22,36]$.

Facilitating: includes developing thoughtful and stimulated questions and raising issues to encourage active participation of students or to use online resources. E-tutors also improve collaborative learning conditions and gives direct instructions in form of content related information about tasks, summing up and confirming postings, clearly communicated expectations about presence and participation (e.g. to take on more responsibility or management roles), encouraging students to work together or emphasizing norms of behavior $[6,14,29]$.

Teaching Design: The e-tutor is responsible for the design of online units within the collaborative courses. This concerns the didactical design of each part of a collaborative course with its respective desired learning objectives and outcomes. Goold et al. [21] emphasize that only experienced e-tutors deal with specific teaching methods and learning strategies. Teaching design involves tasks of setting exercises, providing assessment, developing strategies for structuring the online course as well as timely and strategic interventions for issues that may arise. Therefore, the etutor is responsible for a clear presentation of the designed online instructions to the students to facilitate their growing understanding of course content. According to Essuman \& Appiah-Boateng [14], the tasks can be classified in managerial and pedagogical teaching design. The focus of managerial teaching tasks is on the provision of contents and objects (e.g. online learning tasks or interactive material), setting of timelines and curriculums as well as defining rules and roles in the context of online group collaboration. Pedagogical teaching tasks especially include the provision of insights from the subject knowledge and experience using questions to encourage students' responses. Furthermore, the cognitive task management requires students to actively engage in processing information [14, 23, 51].

Access Management: E-tutors support students work in online collaborative learning environments by identifying and providing access to information resources. At the beginning of an online course, they first ensure that all participants can access to the networking systems and stored materials. During the online phase, e-tutors deal with issues of learner registration, security, record keeping and locating alternative paths $[14,19,41]$.

Moderation: As part of the interaction through online communication, e-tutors lead groups of students as an online moderator. Their field of responsibilities includes opening and maintaining focused discussions, facilitating multi-threaded discourses and chat debates (e.g. identifying areas of agreement and disagreement) and clarifying discussed theories and arguments. According to Lee et al. [33], they are able to direct discussions in a way that effectively stimulates critical thinking among the students $[21,33,52]$.

Feedback: The main responsibility within this task is providing appropriate feedback on submitted materials [14] and the students' work by observation during class [18]. Additionally, the e-tutors are responsible to support the students in the reflection of learning activities and outcomes [36] and to discuss their work together with the learners. Finally yet importantly, this task implies checking the learning progress of students by using assessment methods [51] and as a result grading assignments and results of the students [21].

Social Support: Within online collaborative learning environments, e-tutors influence informal communication through personal attributes (e.g. being sensitive to others, open-mindedness, accuracy seeking). Social support starts right at the beginning of an online meeting when the e-tutors provide a welcoming atmosphere and learning environment for students. Furthermore, they provide support in online discussions, videoconferences, and online collaboration processes by building up a dialogical relationship, offering advice and contributing positively to the wellbeing of online learning groups with attention to details. Research suggests that students participate more actively in discussions, where they are encouraged in a friendly social environment with e-tutors acknowledging their input and providing opportunities for group cohesiveness to develop [7, 11, 14, 21].

Learning Analytics: In the field of online collaborative learning environments, systematic processes of data collection, measurement and analysis can take place. The purpose of learning analytics is to understand and assess the interactions of students in online courses more effectively. With data analysis, certain models can be developed to tailor the teaching style to the needs of students in the course (e.g. providing feedback) [10]. In this context, e-tutors take on the role of observers to monitor and evaluate online collaboration processes and individual behavior of students. For example, they can intervene in group discussions if necessary $[13,29]$. 
Organizational Support: includes answering organizational questions (e.g. grading or processes) and clarifying the course structure $[29,36]$.

Academic Support: In the online collaborative environment, the e-tutors play an intermediary and advisor role [53]. Students receive answers content questions (e.g. provision of literature or unclear tasks) [34] as the e-tutors are considered experts in these areas [1]. Even if e-tutors cannot be available continuously, they are responsible for reacting to students' queries as soon as possible [23]. In addition, the e-tutors can intervene in online discussions if there are uncertainties [14]. If it is necessary, the e-tutors have the opportunity to ask follow up questions, gaining more background information to be able to answer the actual question adequately [38].

Technical Support: Actions of this task are mainly initiated by requests from students who have a technical problem. Therefore, the e-tutors must possess technological skills and "skills in navigating course software" [1] in order to be able to answer the queries. Questions concerning the technology can be related to the access to the system or to the application of individual functions. In addition to responding to inquiries, the tutor is also responsible for providing independent technical support with tools and other issues [13]. In order to simplify the handling of these matters, it is possible, for instance, to create a guideline for online activities in online collaborative environments [8]. Monitoring the occurrence of the students' problems helps to improve the applied system and thus the future common work in virtual learning rooms. At the same time, the e-tutors empower the learners to handle the technology independently [14].

Learning: As part of the learning process, the etutors can accompany the course until the end as a colearner [12]. This includes calling the students by their name, revealing personal details about himself and creating a humorous relationship between students and the e-tutors [1].

Research: In the field of action research, the e-tutors evaluate the course progress from the perspective of a research project [12]. Furthermore, producing new knowledge for the taught content ranks among the tasks of a researcher in this context [19].

\section{Conversational Tasks for a Virtual Tutor}

\subsection{Assessment of identified tasks}

Based on the tasks and conditions defined above, under which the application of conversational agents is reasonable, goals of the conversations can be derived. These should be carried out by the virtual tutor conversational agent. The first column of Table 1 shows the identified tasks from the literature review, which were explained in section 5. Columns 2-5 include the requirements for the use of conversational agents, described in chapter 4.2, to which each task is evaluated (Communication Task, Initiated by Student, Action Based on Existing Data, Clear Reaction Process).

The answer options for each task evaluation are: 'Yes', 'No' or 'Partially'. The tasks of the e-tutor can only be carried out by the conversational agent if all answers are 'Yes' or at least Partially. Furthermore, tasks other than communication tasks cannot be performed by a conversational agent since it requires an interaction based on dialogs. In this case, the other three criteria are not examined, and the respective cell is marked with a dash.

The missing communication in a task affects learning analytics, as it is used for data collection and the three groups of tasks teaching design, learning and research, as they, primarily, can be conducted by the etutors alone and therefore no direct interaction with the students is needed. Learning analytics data are used for interaction with the students in the other tasks.

The circumstances are similar for scheduling, facilitating, and teaching design. All three can be partially identified as communication tasks but are mainly planning tasks. In both cases the communication is not initiated by the student and question from students are grouped in the organizational questions task. Therefore, these tasks are not suitable for automation by conversational agent.

For the research task in the context of Virtual Collaborative Learning courses, communication takes place only on the part of the researchers or only observation is carried out. Since there is no communication initiated by the student, this task is also not suitable for conversational agents.

As moderation, feedback and social support heavily depend on teachers and students and their relationship with one another, it is difficult to create a complete database in advance. Moreover, the difficulty is to fully reflect the human characteristics that occur in these tasks analyzed by the literature above. For this reason, this task can only be automated partially and based on existing data as no clear reaction process is given.

In contrast, organizational, academic and technical support are mainly initiated by the students, so that the challenges they encounter may be solved. Also, these tasks can be dealt with based on existing processes and data in most cases and only need to be handed to a human for more complex matters. This can be assumed based on experience collected in technical support and conversational agents in user support on websites [4]. 
Table 2. Tasks and requirements for conversational agents matrix

\begin{tabular}{|c|c|c|c|c|c|}
\hline \multirow[b]{2}{*}{ Task } & \multicolumn{4}{|c|}{ Requirements for the Use of Conversational agents } & \multirow{2}{*}{ Result } \\
\hline & $\begin{array}{c}\text { Communication } \\
\text { Task? }\end{array}$ & $\begin{array}{l}\text { Initiated by } \\
\text { Student? }\end{array}$ & $\begin{array}{c}\text { Action Based on } \\
\text { Existing Data? }\end{array}$ & $\begin{array}{c}\text { Clear Reaction } \\
\text { Process? }\end{array}$ & \\
\hline Scheduling & Partially & No & Partially & No & $x$ \\
\hline Facilitating & Partially & No & No & No & $x$ \\
\hline $\begin{array}{l}\text { Teaching } \\
\text { Design }\end{array}$ & No & - & - & - & $x$ \\
\hline $\begin{array}{l}\text { Access } \\
\text { Management }\end{array}$ & Yes & Yes & Yes & Yes & $\checkmark$ \\
\hline Moderation & Yes & Yes & Partially & No & $x$ \\
\hline Feedback & Yes & No & Partially & No & $x$ \\
\hline Social Support & Yes & Partially & Partially & No & $x$ \\
\hline $\begin{array}{l}\text { Learning } \\
\text { Analytics }\end{array}$ & No & - & - & - & $x$ \\
\hline $\begin{array}{l}\text { Organizational } \\
\text { Support }\end{array}$ & Yes & Yes & Yes & Yes & $\checkmark$ \\
\hline $\begin{array}{l}\text { Academic } \\
\text { Support }\end{array}$ & Yes & Yes & Partially & Partially & $\checkmark$ \\
\hline $\begin{array}{l}\text { Technical } \\
\text { Support }\end{array}$ & Yes & Yes & Yes & Yes & $\checkmark$ \\
\hline Learning & No & - & - & - & $x$ \\
\hline Research & No & - & - & - & $x$ \\
\hline
\end{tabular}

\subsection{Virtual tutor framework}

Based on this analysis, it is now possible to define a virtual tutor that can support students and relieve etutors (Figure 1). The technical basis is a conversational agent, integrated into the active online learning environment. It can answer queries and requests through dialogue flows and generate responses based on existing data in the course environment. From a technical point of view, the conversational agent should use machinelearning algorithms to identify the user's request and generate an answer based on predefined rules, while using third-party systems as a data source. The answer may be either a direct response or a dialog flow to gather further information, providing the user with suitable help.
From a content perspective, the accepted inputs can be divided into two objectives. On one hand, these are queries that aim to provide the answer to a specific question. This includes Organizational Questions, Technical Support and Content Question. Such questions are, for example: "When does the next lesson take place?", "What does the exam in this course look like?", and "Which sources can I use for task X?", "Is there an expert I can ask on topic Y?" or "Where can I find help for problems with system Z?". For each of these question categories, an existing and a data source for the specific course must be identified to develop the answer logic or to define a dialog flow. On the other hand, there are access management tasks. These are requests like "I need access from system X" or "Can I get access to document Y?". In addition, the conversational agent should give a friendly user 


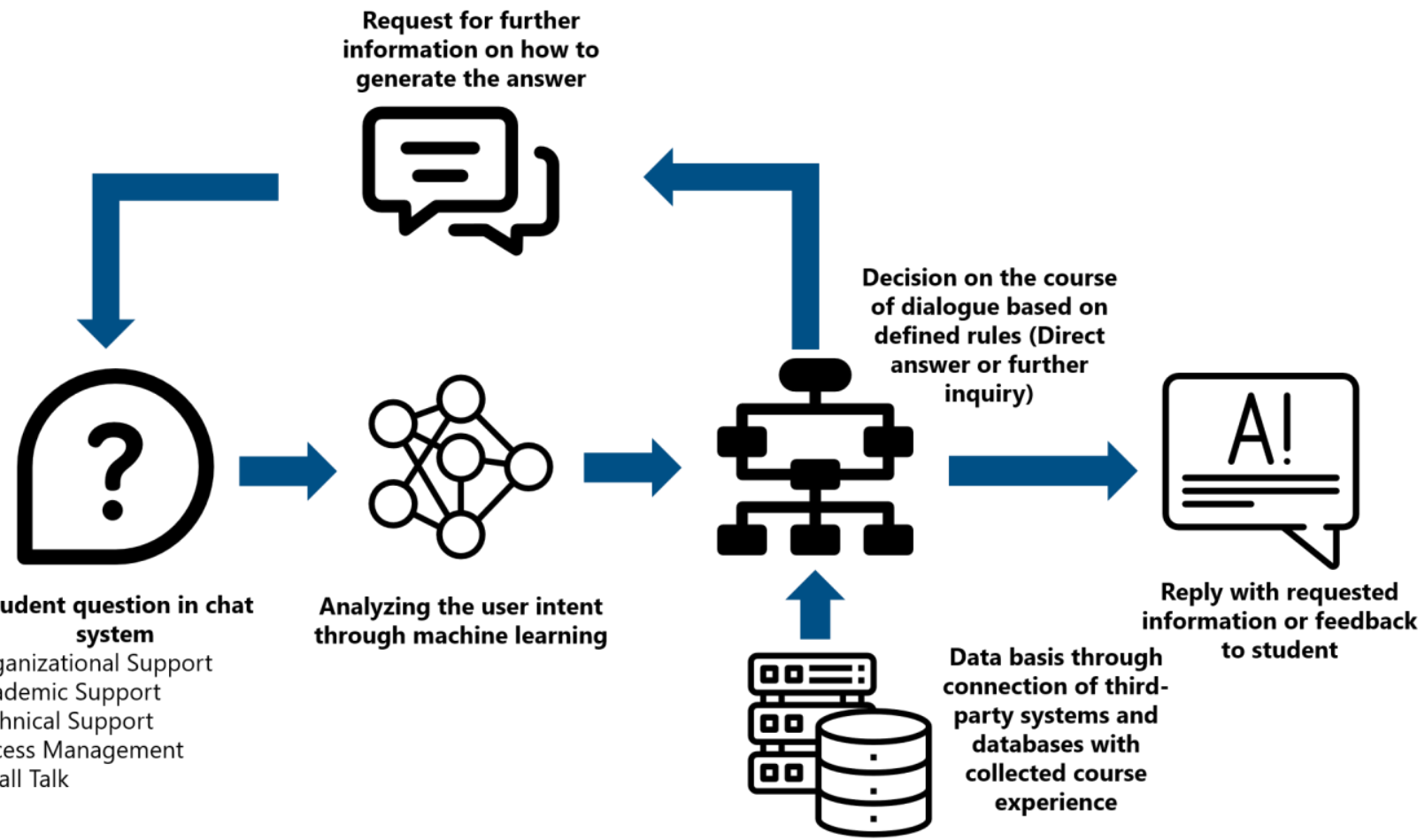

Figure 1. Virtual tutor framework

experience to the students. This means that the conversational agent should support small talk to a certain extent and must be able to master the basic rules of social interaction [2]. Furthermore, the conversational agent should be able to collect feedback, which is directed towards the design of the course and can deal with unexpected input and errors.

Combining the technical structure and tasks of the conversational agent results in a model where students can ask questions in the areas of organizational, academic, and technical support. These questions are entered in text form in the online collaborative learning environment chat system and rules are assigned by the conversational agent to imitate the approach of e-tutors. Based on these rules, third-party systems (such as a course database or the course forum) are then used to analyze whether the question can be answered directly or whether further queries are necessary.

\section{Conclusion}

In this research study, we identified tasks for etutors in an online collaborative learning environment. Furthermore, we mapped them with requirements for the use of conversational agents, showing which tasks can be automated. To illustrate the final concept based on these findings, a virtual tutor framework, in which the automated tasks for the conversational agent are reflected, was developed.

This research paper provides theoretical as well as practical implications for the development of conversational agents in an online collaborative learning environment. The theoretical contribution is a synthesis the scientific literature regarding teaching tasks for online collaborative learning environments. The literature review and the following analysis showed that especially tasks in organization, question answering and reacting to learning analytics results are suitable. To ensure a good user experience, the automatized tasks must be complemented by general functions. By implementing these task packages, it is possible to disencumber e-tutors in online courses, allowing for more individual support of course participants.

The practical contribution is the analysis of the automatisation potential of tasks and the virtual tutor framework, which are the basis for further development of a conversational agent prototype. This gives a starting point for researchers interested in developing virtual tutors for online collaborative learning environments.

This publication focuses on a generalized view on tasks of e-tutors in online collaborative learning environments rather than detailing how conversational agents can convey course-related content. Generally, online collaborative learning environments can be used to transmit any kind of course content as long as the didactical perspective includes collaborative elements. 
Several paths can commence from this study. Based on the results, a conversational agent, carrying out the tasks, needs to be developed. Following the design science approach, this agent should be evaluated regarding the extent to which the tasks are successfully executed. Furthermore, a possible evaluation objective is to conduct a performance assessment of the users with control groups, investigating if the conversational agent supports the collaborative learning processes.

Furthermore, a conversational agent could be triggered by data collected from the online learning platform. Events for the conversational agents can be defined by processing this data. This could enable the conversational agent to actively approach students to make suggestions or comments without relying on student input. Thereby, the student does not initiate the first contact but the processed data signals the conversational agent if an action is needed. This could help maintain or even increase activity, communication and motivation.

\section{References}

[1] Barker, A., "Faculty development for teaching online: Educational and technological issues", The Journal of Continuing Education in Nursing 34(6), 2003, pp. 273-278.

[2] Bickmore, T., and J. Cassell, "Small talk and conversational storytelling in embodied interface agents", Proceedings of the AAAI Fall Symposium on" Narrative Intelligence, (1999).

[3] Bouras, C., and T. Tsiatsos, "Educational virtual environments: design rationale and architecture", Multimedia tools and applications 29(2), 2006, pp. 153-173.

[4] Brandtzaeg, P.B., and A. Følstad, "Why people use chatbots", International Conference on Internet Science, (2017), 377-392.

[5] Bukvova, H., C. Lehr, C. Lieske, P. Weber, and E. Schoop, "Gestaltung virtueller kollaborativer Lernprozesse in internationalen Settings", Multikonferenz

Wirtschaftsinformatik 2010, 2010, pp. 287.

[6] Chang, C., H.-Y. Shen, and E.Z.-F. Liu, "University faculty's perspectives on the roles of e-instructors and their online instruction practice", International Review of Research in Open and Distributed Learning 15(3), 2014, pp. 72-92.

[7] Cheung, W.S., and K.F. Hew, 'Examining facilitators' habits of mind in an asynchronous online discussion environment: A two cases study", Australasian Journal of Educational Technology 26(1), 2010.

[8] Clark, J., "Stimulating collaboration and discussion in online learning environments", The Internet and Higher Education 4(2), 2001, pp. 119-124.

[9] Clauss, A., F. Lenk, and E. Schoop, "Digitalisation and Internationalisation of Learning Processes in Higher

Education", International Conference on e-Learning and $e$ Teaching, (2019).

[10] Clauss, A., F. Lenk, and E. Schoop, "Enhancing International Virtual Collaborative Learning with Social
Learning Analytics", 2019 2nd International Conference on new Trends in Computing Sciences (ICTCS), (2019), 1-6. [11] Conrad, D., "Building and maintaining community in cohort-based online learning", International Journal of ELearning \& Distance Education/Revue internationale du elearning et la formation à distance 20(1), 2005, pp. 1-20. [12] Denis, B., P. Watland, S. Pirotte, and N. Verday, "Roles and competencies of the e-tutor", Networked learning 2004: $A$ research based conference on networked learning and lifelong learning: Proceedings of the fourth international conference, Lancaster, (2004), 150-157.

[13] Easton, S.S., "Clarifying the instructor's role in online distance learning", Communication Education 52(2), 2003, pp. 87-105.

[14] Essuman, S.O., and P. Appiah-Boateng, "Maintaining an Effective Online Learning Environment and the Role of the E-Tutor: The University of Education, Winneba Experience", group 2(1), 2015.

[15] Feidakis, M., P. Kasnesis, E. Giatraki, C. Giannousis, C.Z. Patrikakis, and P. Monachelis, "Building Pedagogical Conversational Agents, Affectively Correct.", CSEDU (1), (2019), 100-107.

[16] Fiore, D., C. Thiel, and M. Baldauf, "Potenziale von Chatbots für den innerbetrieblichen IT-Support", $H M D$ Praxis der Wirtschaftsinformatik 57(1), 2020, pp. 77-88. [17] Galitsky, B., "Chatbot Components and Architectures", In Developing Enterprise Chatbots. Springer, 2019, 13-51.

[18] Goodyear, P., L. Carvalho, and N.B. Dohn, "Design for networked learning: framing relations between participants' activities and the physical setting", Proceedings of the 9th international conference on networked learning, (2014), 137-144.

[19] Goodyear, P., G. Salmon, J.M. Spector, C. Steeples, and S. Tickner, "Competences for online teaching: A special report", Educational Technology Research and Development 49(1), 2001, pp. 65-72.

[20] Google, "Google - AI \& Machine Learning Products", 2020. https://cloud.google.com/dialogflow/docs/intentsoverview

[21] Goold, A., J. Coldwell, and A. Craig, "An examination of the role of the e-tutor", Australasian journal of educational technology 26(5), 2010.

[22] Gretsch, S., J. Hense, and H. Mandl, "Evaluation eines Schulungsprogramms zur Ausbildung von E-Tutoren”, Evaluation von eLernprozessen, 2010, pp. 143-169.

[23] Gulbahar, Y., and F. Kalelioglu, "Competencies for eInstructors: How to qualify and guarantee sustainability", Contemporary Educational Technology 6(2), 2015, pp. 140154.

[24] Hayashi, Y., "Multiple pedagogical conversational agents to support learner-learner collaborative learning: Effects of splitting suggestion types”, Cognitive Systems Research 54, 2019, pp. 246-257.

[25] Haythornthwaite, C., "Facilitating Collaboration in Online Learning”, Online Learning 10(1), 2006, pp. 7-24. [26] Hmelo-Silver, C.E., C.A. Chinn, and C. Chan, The international handbook of collaborative learning, Routledge, 2013.

[27] Hobert, S., and R. Meyer von Wolff, "Say Hello to Your New Automated Tutor - A Structured Literature Review on Pedagogical Conversational Agents", 14th International 
Conference on Wirtschaftsinformatik, (2019).

[28] Jödicke, C., H. Bukvova, and E. Schoop, VirtualCollaborative-Learning-Projekte. Der Transfer des Gruppenlernens in den virtuellen Klassenraum, 2014. [29] De Jong, N., D.M.L. Verstegen, and K.D. Könings, "The role of the e-tutor in synchronous online problem-based learning: A study in a Master Public Health Programme", British Journal of Educational Technology 49(3), 2018, pp. 385-397.

[30] Joshi, N., "Choosing Between Rule-Based Bots And AI Bots", 2020.

https://www.forbes.com/sites/cognitiveworld/2020/02/23/cho osing-between-rule-based-bots-and-ai-bots/\#1722901a353d [31] Kerry, A., R. Ellis, and S. Bull, "Conversational agents in E-Learning", International Conference on Innovative Techniques and Applications of Artificial Intelligence, (2008), 169-182.

[32] Kirschner, P.A., J. Sweller, and R.E. Clark, "Why minimal guidance during instruction does not work: An analysis of the failure of constructivist, discovery, problembased, experiential, and inquiry-based teaching", Educational psychologist 41(2), 2006, pp. 75-86.

[33] Lee, H.-J., Y. Hong, and H. Choi, "Perceptions of tutoring roles and psychological distance among instructors, tutors and students at a Korean university", Higher Education Research \& Development 36(1), 2017, pp. 143157.

[34] Liu, H., R. Macintyre, and R. Ferguson, "Exploring qualitative analytics for e-mentoring relationships building in an online social learning environment", Proceedings of the 2nd International Conference on Learning Analytics and Knowledge, (2012), 179-183.

[35] Maor, D., "Changing relationship: Who is the learner and who is the teacher in the online educational landscape?", Australasian Journal of Educational Technology 24(5), 2008. [36] De Metz, N., and A. Bezuidenhout, "An importance-competence analysis of the roles and competencies of etutors at an open distance learning institution", Australasian Journal of Educational Technology 34(5), 2018.

[37] Mosquera, L.H., "Impact of Implementing a Virtual Learning Environment (VLE) in the EFL Classroom", Íkala: Revista de Lenguaje y Cultura 22(3), 2017.

[38] Nandi, D., M. Hamilton, S. Chang, and S. Balbo, "Evaluating quality in online asynchronous interactions between students and discussion facilitators", Australasian Journal of Educational Technology 28(4), 2012.

[39] Ng, C.S.L., and W.S. Cheung, "Comparing face to face, tutor led discussion and online discussion in the classroom", Australasian Journal of Educational Technology 23(4), 2007. [40] Oracle, "Digital Assistent - What is a Chatbot", 2020. https://www.oracle.com/solutions/chatbots/what-is-a-chatbot/ [41] Pedersen, S., and M. Liu, “Teachers' beliefs about issues in the implementation of a student-centered learning environment", Educational Technology Research and
Development 51(2), 2003, pp. 57.

[42] Peffers, K., T. Tuunanen, M.A. Rothenberger, and S. Chatterjee, "A design science research methodology for information systems research", Journal of management information systems 24(3), 2007, pp. 45-77.

[43] Rainie, L., and J. Anderson, "The Future of Jobs and Jobs Training.", Pew Research Center, 2017.

[44] Sansonnet, J.-P., D. Leray, and J.-C. Martin, "Architecture of a framework for generic assisting conversational agents", International Workshop on Intelligent Virtual Agents, (2006), 145-156.

[45] Schlobinski, P., and T. Siever, "Sprachliche Kommunikation in der digitalen Welt. Eine repräsentative Umfrage, durchgeführt von forsa”, Networx; 80, 2018. [46] Schoop, E., A. Clauss, and A.A. Safavi, "A Framework to Boost Virtual Exchange through International Virtual Collaborative Learning: The German-Iranian Example", Virtual Exchange Borderless Mobility between the European Higher Education Area and Regions Beyond Selection of Conference Papers Presented on December 11, 2019, Erasmus+ National Agency for EU Higher Education Cooperation DAAD Deutscher Akademischer Austauschdienst (2020), 19-29.

[47] Singh, A., K. Ramasubramanian, and S. Shivam, Building an enterprise chatbot: Work with protected enterprise data using open source frameworks, Springer, 2019.

[48] Skoglund, M., and P. Runeson, "Reference-Based Search Strategies in Systematic Reviews", Proceedings of the 13th International Conference on Evaluation and Assessment in Software Engineering, BCS Learning \& Development Ltd. (2009), 31-40.

[49] Spierling, U., and J. Luderschmidt, "Chatbots und mediengestützte Konversation”, In Media Management. Springer, 2018, 387-408.

[50] Stucki, T., S. D’Onofrio, and E. Portmann,

"Theoretische Grundlagen zu Chatbots", In Chatbots gestalten mit Praxisbeispielen der Schweizerischen Post. Springer, 2020, 3-10.

[51] Vonderwell, S., and S. Zachariah, "Factors that influence participation in online learning", Journal of Research on Technology in education 38(2), 2005, pp. 213230.

[52] Wallace, R.M., "Online learning in higher education: A review of research on interactions among teachers and students", Education, Communication \& Information 3(2), 2003, pp. 241-280.

[53] Wilson, G., and E. Stacey, "Online interaction impacts on learning: Teaching the teachers to teach online", Australasian journal of educational technology 20(1), 2004. [54] Winkler, R., and M. Soellner, "Unleashing the potential of chatbots in education: A state-of-the-art analysis", 2018. 